\title{
Analisis Strategi Promosi dan Kualitas Pelayanan Terhadap Kepuasan Pengguna Best Car Care Bogor
}

\author{
Vina Islami, Rani", Syahrir \\ Fakultas Ekonomi dan Bisnis, Administrasi Bisnis, Universitas Bina Sarana Informatika, Jakarta, Indonesia \\ Email: ${ }^{1}$ vina.vii@bsi.ac.id, 2,"rani.rxa@bsi.ac.id, ${ }^{3}$ syahrir.syr@bsi.ac.id \\ Submitted: 01/10/2021; Accepted: 29/10/2021; Published: 30/10/2021
}

\begin{abstract}
Abstrak-Berkembangnya industri otomotif juga turut mendorong berkembangnya industri jasa pendukung seperti bengkel mobil, salon mobil, tempat penjualan suku cadang, tempat penjualan aksesoris dan jasa pencucian mobil. Jasa pencucian mobil sendiri sangat dibutuhkan para pengguna mobil, karenasangat menghemat waktu dan dijamin hasilnya sehingga mobil bisa terawat dengan baik. Dalam menawarkan jasa mereka, para pengusaha harus menerapkan strategi promosi yang tepat. Kualitas pelayanan juga mendukung perusahaan untuk memberikan kepuasan bagi pelanggannya. Tujuan penelitian ini untuk mengetahui pengaruh strategi promosi dan kualitas pelayanan terhadap kepuasan pengguna Best Car Care Bogor secara parsial maupun simultan. Populasi sebanyak 250 orang dan di ambil sampel sebanyak 145 responden. Metode penelitian menggunakan analisis regresi berganda. Hasil penelitian yang dilakukan didapati bahwa strategi promosi dan kualitas pelayanan pengaruh positif dan signifikan baik secara simultan maupun parsial terhadap kepuasan pengguna. Saran bagi pengusaha Best Car Care Bogor agar lebih memperhatikan kepuasan para pengguna jasa Best Car Care Bogor, untuk meningkatkan penggunaan jasa layanan.
\end{abstract}

Kata Kunci: Strategi Promosi; Kualitas Pelayanan; Kepuasan Pengguna

\begin{abstract}
The development of the automotive industry at this time can be quite rapid because every year the number of vehicles continues to increase. The development of the automotive industry also encourages the development of industries supporting services such as car repair shops, car salons, sales of spare parts, the sale of accessories, and car wash services. Own car wash services are needed the car users because, in addition to saving time, the car users are also convinced that if their car is washed at the car wash, the car will be clean and well maintained. In offering their services, employers must implement appropriate promotional strategies. Quality of service also supports the company to provide satisfaction for its customers. The purpose of this study is to determine the effect of promotion strategies and quality of service on user satisfaction at Best Car Care Bogor partially or simultaneously. A population of 220 people and take a sample of 135 respondents. The research method using multiple regression analysis. Results of research conducted found that the promotion strategy and service quality and significant positive effect either simultaneously or partially on user satisfaction. Advice for employers Best Car Care Bogorfor more attention to the satisfaction of the users of services Best Car Care Bogor, to increase the use of services.
\end{abstract}

Keywords: Promotion Strategy; Service Quality; Customer Satisfaction

\section{PENDAHULUAN}

Di kota Bogor saat ini, terdapat beberapa tempat usaha pencucian mobil seperti Autoclean Car Wash yang menyediakan cuci robotic, cuci hidrolik, dan wifi gratis. In-Out Autowash yang menawarkan pencucian mobil dengan menggunakan mesin full automatik yang membersihkan mobil tanpa meninggalkan goresan di mobil dan pencuciannya hanya berlangsung selama 7 menit, serta mempunyai ruang tunggu dan fasilitas free wifi. Kemudian ada juga Auto Spark Car Care yang tidak hanya menyediakan jasa cuci mobil tapi juga menyediakan jasa car spa, poles mobil, vacum, semir, wax dan nano ceramic paint protection. Melihat persaingan bisnis yang semakin ketat, maka peneliti pun tertarik untuk meneliti salah satu tempat usaha pencucian mobil yang ada di Kota Bogor Best Car Care Bogor. Best Car Care Bogor yang menerapkan inovasi yang cukup menarik minat calon pelanggan/pengguna seperti Snow Wash, Platinum Wash, Gold Wash, Car Services.

Kepuasan pelanggan merupakan hal yang sangatpenting bagi perusahaaan dalam upaya memenuhi keinginan dan kebutuhan pelanggan. Kepuasan pelanggan juga tidak terlepas dari strategi promosi dan kualitas pelayanan yang diberikan oleh perusahaan. Karena, jika pelanggan merasa puas bahkan melebihi ekspektasi mereka, maka pelanggan tersebut tidak akan mudah beralih pada perusahaan jasa lain yang sejenis karena keinginan dan kebutuhan mereka telah terpenuhi.

Penelitian terdahulu yang terkait dengan penelitian ini adalah (1) Eka Giovana Asti. 2019. Judul penelitian Analisis Pengaruh Strategi Promosi dan Kualitas Pelayanan Terhadap Loyalitas Konsumen Pada Rumah Makan Saung Wulan. Berdasarkan hasil perhitungan Koefisien korelasi antara Strategi Promosi serta Kualitas Pelayanan secara bersama-sama terhadap Loyalitas Konsumen pada Pengusaha Rumah Makan Saung Wulan , adalah positif dengan tingkat hubungan yang sangat kuat yaitu sebesar 0,866 dan setelah di uji hipotesa dengan uji F korelasi tersebut memiliki hubungan yang signifikan. Hasil uji koefisien regresinya pun menunjukkan hubungan lurus dan positif dilihat dari kontribusi variabel Strategi Promosi serta Kualitas Pelayanan terhadap Loyalitas Konsumen pada Pengusaha Rumah Makan Saung Wulan.(Asti, 2019); (2) Tri Ulfa Wardani, 2017 dengan penelitian Pengaruh Kualitas Pelayanan Terhadap Kepuasan Konsumen Pada Bisnis Jasa Transportasi GOJEK. Metode analisis data yang digunakan adalah analisis kuantitatif yaitu uji validitas dan reliabilitas, uji asumsi klasik, analisis regresi linear berganda, uji t dan uji $\mathrm{F}$ serta koefisien determinasi. Berdasarkan analisis data, hasil penelitian menunjukkan bahwa indikator-indikator pada pada penelitian ini bersifat valid dan reliabel. Pada uji asumsi klasik data berdistribusi normal, tidak terjadi heteroskedastisitas dan multikolinieritas. Pada uji hipotesis tangible, responsiveness, assurance dan emphaty tidak 
berpengaruh signifikan terhadap kepuasan konsumen. Dan uji hipotesis reliability memiliki pengaruh positif dan signifikan terhadap kepuasan konsumen (Wardani, 2017).

Perbedaaan dengan peneltian terdahulu terletak pada lokasi penelitian dan jenis tempat penelitian. Biasanya penelitian dilakukan pada rumah makan atau jasa yang sejenis, namun penulis tertarik meneliti disektor usaha jasa pencucian mobil, karena secara tidak sadar, jasa ini sangat dibutuhkan konsumen sehingga perusahaan perlu merumus akan strategi promosi yang paling tepat dan apakah pelayanan yang diberikan sudah memenuhi kepuasan pelanggan perusahaan.

Adanya penelitian ini, tentu bermanfaat bagi Best Car Care Bogor, apakah strategi promosi yang dilakukan sudah tepat dan apakah pelanggan puas dengan kualitas dari pelayanan Best Car Care Bogor.

\section{KERANGKA TEORI}

\subsection{Promosi}

Promosi merupakan fungsi pemasaran yang fokus untuk mengkomunikasikan program-program pemasaran secara persuasif kepada target pelanggan atau calon pelanggan untuk mendorong terciptanya transaksi-pertukaran antara perusahaan dan pelanggan (Hasan, 2014, p. 603). Promosi merupakan suatu usaha perusahaan untuk mempengaruhi dan merayu (persuasive communication) calon pembeli, melalui pemakaian segala unsur acuan pemasaran (Assauri, 2014, p. 265). Dengan demikian dapat disimpulkan bahwa promosi adalah kegiatan pemasaran yang bertujuan untuk menginformasikan dan mendorong permintaan terhadap, produk, jasa, dan ide dari perusahaan dengan cara mempengaruhi para pelanggan sasaran agar mau membeli barang dan jasa yang dihasilkan oleh perusahaan.

\subsection{Kualitas Pelayanan}

Kualitas pelayanan merupakan konsep yang abstrak dan sukar dipahami, karena kualitas pelayanan memiliki karakteristik tidak berwujud, bervariasi, tidak tahan lama, serta produksi dan konsumsi jasa terjadi secara bersamaan (Tjiptono, 2014, p. 172). Kualitas pelayanan adalah segala bentuk aktivitas yang dilakukan oleh perusahaan guna memenuhi harapan konsumen. Pelayanan dalam hal ini diartikan sebagai jasa atau service yang disampaikan oleh pemilik jasa yang berupa kemudahan, kecepatan, hubungan, kemampuan dan keramahtamahan yang ditujukan melalui sikap dan sifat dalam memberikan pelayanan untuk kepuasan konsumen (Harahap, Z., Agus S.Soegoto., 2014, p. 861). Dengan demikian kualitas pelayanan ditentukan oleh kemampuan perusahaan memenuhi kebutuhan dan keinginan pelanggan sesuai dengan ekspektasi pelanggan.

\subsection{Kepuasan Pelanggan}

Kepuasan pelanggan mencerminkan penilaian seseorang tentang kinerja (hasil) produk anggapannya dalam kaitannya dengan ekspektasi. Jika kinerja produk tersebut tidak memenuhi ekspektasi, pelanggan tersebut senang (Kotler, 2012, p. 176). Ada beberapa elemen program kepuasan pelanggan (Tjiptono, 2014), yaitu: barang dan jasa berkualitas, relationship marketing, program promosi loyalitas, fokus pada pelanggan terbaik, sistem penanganan komplain secara interaktif, program pay-for-performance. Dengan demikian dapat disimpulkan bahwa kepuasan pelanggan merupakan hasil dari penilaian konsumen mengenai produk yang dikonsumsinya/digunakannya.

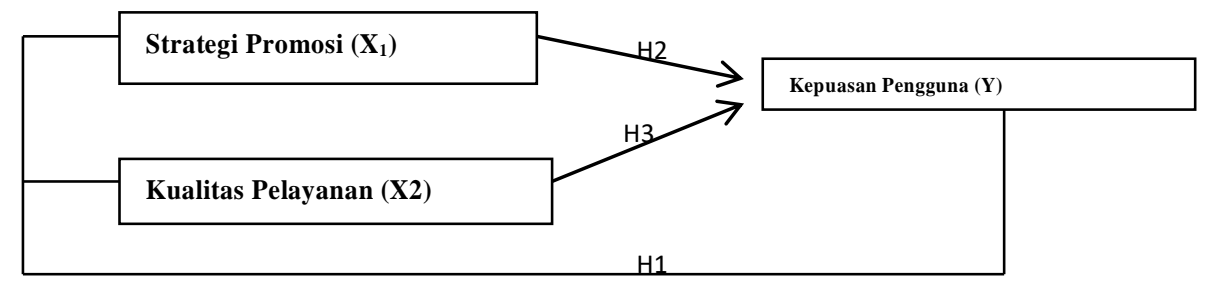

Gambar 1. Kerangka Berpikir Penelitian

\subsection{Hipotesis Penelitian}

$\mathrm{H}_{1}$ : Strategi promosi dan kualitas pelayanan diduga secara simultan berpengaruh terhadap kepuasan pengguna Best Car Care Bogor.

$\mathrm{H}_{2}$ : Strategi promosi diduga secara parsial mempunyai pengaruh terhadap kepuasan pengguna Best Car Care Bogor

$\mathrm{H}_{3}$ : Kualitas pelayanan diduga secara parsial mempunyai pengaruh terhadap kepuasan pengguna Best Car Care Bogor

\section{METODE PENELITIAN}

\subsection{Jenis Penelitian}

Jenis penelitian yang digunakan adalah penelitian asosiatif yang bertujuan untuk mengetahui pengaruh dua variabel atau lebih (Sugiyono 2014, 55). Dalam penelitian asosiatif, penulis mengambil hubungan kausal yaitu hubungan yang 
bersifat sebab akibat, jadi terdapat variabel indpenden (variabel yang mempengaruhi) dan variabel dependen (variabel yang dipengaruhi).

\subsection{Tempat dan Waktu Penelitian}

Tempat penelitian yaitu di Best Car Care Bogor, Jalan Raya Padjajaran No 63 Bantar Jati, Kecamatan Bogor Utara Kota Bogor. Penelitian ini telah dilaksanakan selama 3 bulan mulai dari Februari 2019 sampai dengan April 2019, baik dari proses melengkapi data, survei di lapangan, hingga proses pengisian angket, setelah itu akan dilanjutkan pada tahap pengolahan data.

\subsection{Metode Pengumpulan Data}

Metode yang digunakan dalam pengumpulan data penelitian ini adalah :

a. Angket

b. Observasi

\subsection{Metode Analisis Data}

\subsubsection{Uji Validitas}

Pengujian validitas tiap butir digunakan analisis item, yaitu mengkorelasikan skor tiap butir dengan skor total yang merupakan jumlah tiap skor butir. Valid tidaknya suatu item instrumen dapat diketahui dengan membandingkan indeks korelasi product moment pearson dengan level signifikasi 5\%. Bila signifikansi hasil korelasi $<0,05(5 \%) \mathrm{maka}$ dinyatakan valid dan sebaliknya dikatakan tidak valid. Setelah data ditabulasikan, maka pengujian validitas konstruk dilakukan dengan analisis faktor, yaitu dengan mengkorelasikan antar skor item instrumen (Sugiyono, 2009, p. 352).

\subsubsection{Uji Reliabilitas}

Uji reliabilitas menunjukkan konsistensi hasil alat ukur dalam mengukur gejala yang sama berulang kali. Alpha Cronbach's merupakan salah satu koefisien yang handal dapat menunjukkan bagaimana setiap item dapat berkorelasi positif satu sama lain. Peneliti menggunakan Alpha Cronbach's tingkat uji reliabilitas penggunaan = 0,05. Dalam menganalisis validitas dan reliabilitas, peneliti menggunakan aplikasi SPSS 16.0. Dalam aplikasi SPSS juga dilakukan uji Multikolienaritas, Uji Heterokedastisitas

\subsubsection{Analisis Regresi Linear Berganda}

Analisis yang digunakan oleh peneliti dengan maksud untuk meramalkan bagaimana keadaan variabel dependen, bila dua atau lebih variabel indpenden sebagai faktor prediktor di manipulasi (di naik turunkan nilainya). Jadi, analisis regresi linier berganda akan dilakukan bila jumlah variabel independennya minimal dua.Persamaan regresi dalam penelitian ini adalah untuk mengetahui seberapa besar pengaruh variabel independen yaitu strategi promosi $\left(\mathrm{X}_{1}\right)$ dan kualitas pelayanan $\left(\mathrm{X}_{2}\right)$, terhadap kepuasan pengguna (Y)Car CareCenter (C3) Car Wash.Uji Signifikasi Simultan (Uji F). Uji F hitung digunakan untuk menguji ketepatan model (Goodness of fit). Uji F ini juga sering disebut sebagai uji simultan, untuk menguji apakah variabel bebas yang digunakan dalam model mampu menjelaskan perubahan nilai variabel tergantung atau tidak. Dalam penelitian ini pengujian hipotesis secara simultan dimaksudkan untuk mengukur besarnya pengaruh promosi dan kualitas pelayanan untuk menyimpulkan apakah model masuk dalam kategori cock (fit) atau tidak, kita harus membandingkan nilai F hitung dengan nilai F tabel dengan derajat bebas. Uji Signifikasi Parsial (Uji T). Uji t hitung digunakan untuk menguji apakah variabel tersebut berpengaruh secara signifikan terhadap variabel tergantung atau tidak. Suatu variabel akan memiliki pengaruh yang berarti jika nilai t hitung variabel tersebut lebih besar dibandingkan dengan nilai t tabel. Uji Korelasi (R). Analisis koefisien korelasi (R) ini digunakan untuk mengukur keeratan hubungan antara variabel bebas $(\mathrm{X})$ terhadap variabel terikat $(\mathrm{Y})$, dalam hal ini mengukur kuat lemahnya hubungan Promosi $\left(\mathrm{X}_{1}\right)$ dan Kualitas Pelayanan $\left(\mathrm{X}_{2}\right)$ dengan Kepuasan Pengguna/Pelanggan (Y)Best Car Care Bogor dan Uji Determinasi $\left(R^{2}\right.$. Koefisien determinasi $\left(R^{2}\right)$ diperlukan untuk menghitung selisih nilai $Y$ riil dengan nilai $Y$ prediksi dan nilai kuadrat nilai $\mathrm{Y}$ riil dengan nilai $\mathrm{Y}$ rata-rata.

\section{HASIL DAN PEMBAHASAN}

\subsection{Hasil Penelitian}

\subsubsection{Uji Validitas}

Pengujian validitas tiap butir digunakan analisis item, yaitu mengkorelasikan skor tiap butir dengan skor total yang merupakan jumlah tiap skor butir.

Tabel 1. Hasil Uji Validitas

\begin{tabular}{lccc}
\hline \multicolumn{1}{c}{ Variabel } & Pernyataan & Sig & Status \\
\hline $\begin{array}{l}\text { Strategi Promosi }\left(\mathrm{X}_{1}\right) \\
\text { Indikator 1 }\end{array}$ & $\mathrm{X} 1-1$ & & \\
\end{tabular}


Journal of Business and Economics Research (JBE)

Vol 2, No 3, Oktober 2021, Hal. 74-79

ISSN 2716-4128 (Media Online)

DOI 10.47065/jbe.v2i3.881

\begin{tabular}{lccc}
\hline \multicolumn{1}{c}{ Variabel } & Pernyataan & Sig & Status \\
\hline Indikator 2 & $\mathrm{X} 1-2$ & 0.000 & Valid \\
Indikator 3 & $\mathrm{X} 1-3$ & 0.000 & Valid \\
Indikator 4 & $\mathrm{X} 1-4$ & 0.000 & Valid \\
Indikator 5 & $\mathrm{X} 1-5$ & 0.000 & Valid \\
Kualitas Pelayanan $\left(\mathrm{X}_{2}\right)$ & & & \\
Indikator 1 & $\mathrm{X} 2-1$ & 0.000 & Valid \\
Indikator 2 & $\mathrm{X} 2-2$ & 0.000 & Valid \\
Indikator 3 & $\mathrm{X} 2-3$ & 0.000 & Valid \\
Indikator 4 & $\mathrm{X} 2-4$ & 0.000 & Valid \\
Indikator 5 & $\mathrm{X} 2-5$ & 0.000 & Valid \\
Kepuasan Pengguna (Y) & & & \\
Indikator 1 & $\mathrm{Y}_{1}$ & 0.000 & Valid \\
Indikator 2 & $\mathrm{Y}_{2}$ & 0.000 & Valid \\
Indikator 3 & $\mathrm{Y}_{3}$ & 0.000 & Valid \\
Indikator 4 & $\mathrm{Y}_{4}$ & 0.000 & Valid \\
Indikator 5 & $\mathrm{Y}_{5}$ & 0.000 & Valid \\
Indikator 6 & $\mathrm{Y}_{6}$ & 0.000 & Valid \\
\hline
\end{tabular}

Sumber: Data yang diproses SPSS 16, 2019

Hasil uji validitas semua pernyataan variabel strategi promosi $\left(\mathrm{X}_{1}\right)$, kualitas pelayanan $\left(\mathrm{X}_{2}\right)$ dan kepuasan pengguna (Y) dinyatakan valid.

\subsubsection{Uji Reliabilitas}

Uji reliabilitas menunjukkan konsistensi hasil alat ukur dalam mengukur gejala yang sama berulang kali. Alpha Cronbach's merupakan salah satu koefisien yang handal dapat menunjukkan bagaimana setiap item dapat berkorelasi positif satu sama lain. Peneliti menggunakan Alpha Cronbach's tingkat uji reliabilitas penggunaan = 0,05. Dalam menganalisis validitas dan reliabilitas, peneliti menggunakan aplikasi SPSS 16.0

Tabel 2. Hasil Uji Reliabilitas

\begin{tabular}{clcc}
\hline No & \multicolumn{1}{c}{ Variabel } & Cronbach's Alpha & Keterangan \\
\hline 1. & Strategi Promosi $\left(\mathrm{X}_{1}\right)$ & 0.816 & Reliable \\
2. & Kualitas Pelayanan $\left(\mathrm{X}_{2}\right)$ & 0.803 & Reliable \\
3. & Kepuasan Pengguna $(\mathrm{Y})$ & 0.787 & Reliable \\
\hline
\end{tabular}

Sumber: Data yang diproses SPSS 16, 2019

Berdasarkan hasil uji reliabilitas, menunjukkan hasil bahwa strategi promosi $\left(\mathrm{X}_{1}\right)$, kualitas pelayanan $\left(\mathrm{X}_{2}\right)$ dan kepuasan pengguna (Y) dengan nilai Cronbach's Alpha> 0.60 sehingga dinyatakan reliable.

\subsubsection{Uji Multikolienaritas}

Uji Multikolienaritas digunakan untuk menunjukkan adanya hubungan linier di antara variabel-variabel bebas dalam model regresi.

Tabel 3. Hasil Uji Multikolienaritas

\begin{tabular}{lcc}
\hline \multicolumn{2}{c}{$\begin{array}{c}\text { Collinearity Statistics } \\
\text { Variable }\end{array}$} & \\
& Tolerance & VIF \\
\hline Strategi Promosi (X1) & 0.664 & 1.507 \\
Kualitas Pelayanan (X2) & 0.664 & 1.507 \\
\hline
\end{tabular}

Sumber : Data diproses SPSS 16, 2019

Hasil uji Multikolienaritas, nilai VIF dari variabel strategi promosi $\left(\mathrm{X}_{1}\right)$ dan kualitas pelayanan $\left(\mathrm{X}_{2}\right)$ yaitu 1.507, maka dapat disimpulkan bahwa tidak terjadi multikolienaritas karena semua nilai $\mathrm{VIF}<10$.

\subsubsection{Analisis Regresi Linear Berganda}

Tabel 4. Hasil Analisis Regresi Linear Berganda

\begin{tabular}{llcc}
\hline Model & & \multicolumn{2}{c}{ Unstandardizer Coefficients } \\
& & B & Std. Error \\
\hline 1 & (Constant) & 10.441 & 2.125 \\
& Strategi Promosi & 0.334 & 0.079 \\
& Kualitas Pelayanan & 0.423 & 0.160 \\
\hline
\end{tabular}

Sumber : Data yang diproses SPSS 16, 2019 


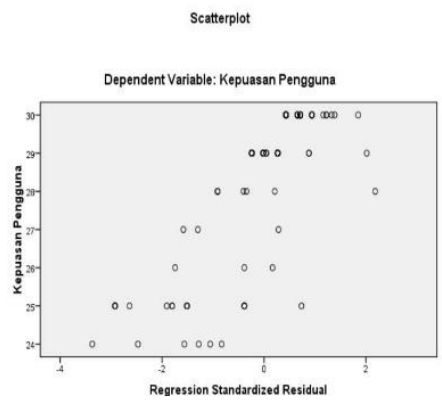

Gambar 2. Hasil Analisis Regresi Linear Berganda Sumber: data yang diproses, 2016

Hasil output pada Tabel 4 maka diperoleh $\mathrm{a}=10.441$, b1 $=0.334$, b2 $=0.423$, maka persamaan regresi linear berganda adalah: $\mathrm{Y}=10.441+0.334 \mathrm{X}_{1}+0.423 \mathrm{X}_{2}+\mathrm{e}$. Dari persamaan yang terbentuk dapat dijelaskan interpretasinya sebagai berikut:

a. a $($ konstanta $)=10.441$, artinya apabila variabel strategi promosi $\left(\mathrm{X}_{1}\right)$ dan kualitas pelayanan $\left(\mathrm{X}_{2}\right)$ dalam keadaan konstan, maka kepuasan pengguna (Y) adalah sebesar 10.441 skala satuan.

b. $b_{1}=0.334$, artinya apabila variabel strategi promosi $\left(\mathrm{X}_{1}\right)$ meningkat 1 skala satuan, maka kepuasan pengguna akan meningkat sebesar 0.334 skala satuan.

c. $b_{2}=0.423$, artinya apabila variabel kualitas pelayanan $\left(\mathrm{X}_{2}\right)$ meningkat 1 skala satuan, maka kepuasan pengguna akan meningkat sebesar 0.423 skala satuan.

\subsubsection{Uji F (Simultan)}

Tabel 5. Hasil Uji Signifikan Simultan (F)

\begin{tabular}{cccccc}
\hline Sum Of & \multicolumn{3}{c}{ Sig. } \\
\cline { 2 - 4 } & Squares & df & Mean Square & F & $0.000^{\mathrm{a}}$ \\
Regression & 178.626 & 2 & 40.130 & \\
Residual & 293.774 & 132 & & \\
Total & 472.400 & 134 & &
\end{tabular}

Hasil output pada Tabel 5 nilai $F$ hitung adalah 40.130. Nilai $F$ tabel diperoleh dari V1 = k, V2 = n-k. Jadi V1 $=4, \mathrm{~V} 2=135-3-1=131=2.60$, maka untuk F hitung $40.130 \geq \mathrm{F}$ tabel 2.60 , jadi variabel independen yaitu strategi promosi $\left(\mathrm{X}_{1}\right)$ dan kualitas pelayanan $\left(\mathrm{X}_{2}\right)$ mempunyai pengaruh yang signifikan secara simultan terhadap variabel dependen yaitu kepuasan pengguna (Y) Best Car Care Bogor.

\subsubsection{Uji T (Parsial)}

Tabel 6. Hasil Uji T (Parsial)

\begin{tabular}{llcc}
\hline \multicolumn{1}{c}{ Model } & T & Sig. \\
\hline 1 & (Constant) & 4.914 & 0.000 \\
& Strategi Promosi & 4.221 & 0.000 \\
& Kualitas Pelayanan & 3.990 & 0.000 \\
\hline \multicolumn{2}{c}{ Sumber : Data yang diproses SPSS 16, 2019 }
\end{tabular}

Nilai signifikan $\geq 0.05$ maka $\mathrm{H}_{0}$ diterima, jika nilai signifikan $\leq 0.05$, maka $\mathrm{H}_{0}$ ditolak dan $\mathrm{H}_{\mathrm{a}}$ diterima. Nilai dari hasil variabel strategi promosi $\left(\mathrm{X}_{1}\right)=0.000 \leq 0.05$ atinya $\mathrm{H}_{0}$ ditolak dan $\mathrm{H}_{\mathrm{a}}$ diterima, maka variabel strategi promosi $\left(\mathrm{X}_{1}\right)$ memiliki pengaruh yang signifikan terhadap kepuasan pengguna $(\mathrm{Y})$.Nilai dari variabel kualitas pelayanan $\left(\mathrm{X}_{2}\right)=$ $0.000 \leq 0.05$ artinya $\mathrm{H}_{0}$ ditolak dan $\mathrm{H}_{\mathrm{a}}$ diterima, maka variabel kualitas pelayanan $\left(\mathrm{X}_{2}\right)$ memiliki pengaruh yang signifikan terhadap kepuasan pengguna (Y). Berdasarkan hasil tersebut maka dapat disimpulkan bahwa variabel independen (strategi promosi dan kualitas pelayanan) memiliki pengaruh yang signifikan secara parsial terhadap variabel dependen (kepuasan pengguna).

\subsubsection{Uji Koefisien Korelasi $(R)$ dan Koefisien Determinasi $\left(R^{2}\right)$}

Tabel 7. Hasil Uji Koefisien (R) dan Koefisien Determinasi $\left(\mathrm{R}^{2}\right)$

\begin{tabular}{cccc}
\hline $\mathrm{R}$ & R Square & $\begin{array}{c}\text { Adjusted R } \\
\text { Square }\end{array}$ & Std. Error of the Estimate \\
\hline 0.615 & 0.378 & 0.369 & 1.492 \\
\hline \multicolumn{4}{c}{ Sumber : Data yang diproses SPSS 16, 2019 }
\end{tabular}


Hasil perhitungan dengan menggunakan program SPSS 16 dapat dilihat besarnya koefisien korelasi berganda (r) dari model hubungan antara strategi promosi dan kualitas pelayanan terhadap kepuasan pengguna adalah sebesar 0.615 . Dengan demikian maka pengaruh antara variabel strategi promosi dan kualitas pelayanan terhadap kepuasan pengguna adalah kuat. Untuk melihat besarnya kontribusi dari variabel strategi promosi dan kualitas pelayanan terhadap kepuasan pengguna ditunjukkan oleh besarnya angka koefisien determinasi $\left(\mathrm{r}^{2}\right)$ sebesar 0.378. Angka ini menunjukkan besarnya kontribusi dari variabel strategi promosi dan kualitas pelayanan terhadap kepuasan pengguna Best Car Care Bogor adalah sebesar 0.37 atau $37 \%$ sedangkan sisanya sebesar 0.63 atau $63 \%$ disebabkan oleh variabel lainnya yang tidak diteliti dalam penelitian ini.

\section{KESIMPULAN}

Hasil pengujian secara simultan diketahui bahwa variabel strategi promosi dan kualitas pelayanan secara simultan memiliki pengaruh positif terhadap variabel kepuasan pengguna pada Best Car Care Bogor. Hasil perhitungan analisis regresi linear berganda dengan pengujian parsial diketahui bahwa variabel strategi promosi mempunyai pengaruh secara parsial terhadap kepuasan pengguna Best Car Care Bogor. Hasil perhitungan analisis regresi linear berganda dengan pengujian parsial diketahui bahwa variabel kualitas pelayanan memiliki pengaruh positif dan signifikan terhadap kepuasan pengguna pada Best Car Care Bogor.

\section{DAFTAR PUSTAKA}

Assauri, S. (2014). Manajemen Pemasaran Cetakan ketigabelas. Rajagrafindo Perkasa.

Asti, E. G. (2019). Analisis Pengaruh Strategi Promosi dan Kualitas Pelayanan TErhadap Loyalitas Konsumen Pada Rumah Makan Saung Wulan. Jurnal Pengembangan Wiraswasta, 21 No 1 Ap. http://ejurnal.stieipwija.ac.id/index.php/jpw/article/view/290/pdf

Harahap, Z., Agus S.Soegoto., dan J. J. R. (2014). CITRA MEREK, EKUITAS MEREK, DAN KUALITAS PELAYANAN TERHADAP LOYALITAS KONSUMEN PADA PRODUK INDOMIE DIKECAMATAN MALALAYANG 1 BARAT MANADO. Jurnal EMBA, 2(2303-1174), 859-870.

Hasan, A. (2014). Marketing dan Kasus-Kasus Pilihan Cetakan kedua. CAPS (Center For Academic Publishing Service).

Kotler, P. and K. L. K. (2012). Marketing Management Edisi Keempat belas. Pearson.

Sugiyono. (2009). Metode Penelitian Bisnis Cetakan Kelima Belas. CV Alfabeta.

Sugiyono. (2014). Metode Penelitian Manajemen Cetakan ketiga. CV Alfabeta.

Tjiptono, F. (2014). Pemasaran Jasa. Andy Offset.

Wardani, T. U. (2017). Pengaruh Kualitas Pelayanan TErhadap Kepuasan Konsumen PAda Bisnis Jasa Transportasi GOJEK. http://repository.uinsu.ac.id/3449/1/tri ulfa wardani.pdf 